\title{
Indium In-111 Chloride
}

National Cancer Institute

\section{Source}

National Cancer Institute. Indium In-111 Chloride. NCI Thesaurus. Code C47562.

A radioactive salt that is used as a reagent in the preparation of indium 111-labeled radiopharmaceuticals. Indium 111-labeled radioconjug ates are used as radioactive tracers in nuclear medicine that detect malignant lesions and inflammatory tissues probably due to an increased capillary permeability. Indium-111 chloride is particularly used in the radiolabeling of the monoclonal antibodies satumomab pendetide, 7E11-C5.3 (CYT-356), and ibritumomab tiuxetan. (NCI05) 